\title{
Case Report - Health Promotion for the Hispanic Population
}

\author{
OLIVEIRA, Margaret de [1] \\ DENDASCK, Carla Viana [2]
}

OLIVEIRA, Euzébio de [3]

OLIVEIRA, Margaret de. Case Report - Health Promotion for the Hispanic Population. Multidisciplinary Scientific Journal. Special Edition of Health. Year 02, Issue 11, Vol. 04. pp 79-83, November of 2017. ISSN: 2448-0959

\section{INTRODUCTION}

\section{Health promotion}

My attendance to the Oldtimers Foundation community meeting opened my eyes to how some communities are reaching out to change unhealthy eating habits in the Latino population. This meeting was done in Spanish so the community members would understand and participate in the meeting's goals. However, they provided translation through a device for each participant that did not speak Spanish. The meeting was very interacting and with visual materials such as bottles of sodas with sugar cubes attached to it showing the ridiculous amount of sugar a person is consuming when drinking a soda or a bottle of juice. Providing the culturally relevant interventions by use the community members' main language will most likely ensure compliance (Valen, Narayan \& Wedeking, 2012). Bringing awareness to the Latino population is one of the most important tasks in the recent years.

According to the U.S. Department of Health \& Human Service, childhood obesity affects African American and Mexican American adolescents 21 and 23 percent in comparison with white adolescents 14 percent. The hospital costs were estimated at \$127 million during 1997-1999 comparing to \$35 million during 1979-1981. Adolescents have a 70 percent chance of becoming overweight or obese adults (Bishop, Middendorf, Babin \& Tilson, 2005).

Therefore the aim of this study was to describe a nursing experience report with a community Hispanic, in relation to their eating habits. 


\section{METHODOLOGY}

This study it is an experience report on the practice of nursing in a Hispanic community in relation to health promotion with regard to eating habits of this population. For this lecture with community Hispanic Oldtimers Foundation in Los Angeles was held California -USA Was discussed how some communities are changing their eating habits to unhealthy habits especially in the Latino population This meeting was held in Spanish so that community members could understand and participate and thus meet the objectives of the meeting. However they provided translation through a device for each participant who did not speak Spanish. The meeting was very interactive and visual materials such as soft drink bottles with sugar cubes attached to it showing the large amount of sugar a person is consuming when drinking a soda or a bottle of juice.

\section{RESULTS AND DISCUSSION}

Overall Latinos are now one of the groups with the highest prevalence of obesity in the U.S. In 2010, approximately $31.9 \%$ of the Latino adult population was obese (Schiller, Ward, Peregoy, 2010).

These statistics clearly shows the need to bring awareness to the Hispanic population about changes in eating habits. The community health workers use the My Plate icon which was created in 2011 by the First Lady Michelle Obama and the United States Department of Agriculture (USDA) secretary Tom Vilsack. This icon was created to prompt consumers to make healthy plate during meal times. The plate is simple and guides the consumer to eat the five food groups that are essential in our diet with the emphasis on a larger portion of vegetables and grains. The community health workers are focusing in educating the Hispanic population in making healthier choices, by showing facts about the harming effect of unhealthy diet such as diabetes, heart diseases and other healthy issues. They also educate the community on how to make better food choices during shopping for their food and when socializing with family members and the importance of exercising.

The emphasis on this policy is to start changes by using education in the language that the community members understand to increase compliance. The community members and nurse focused mainly on educating the parents who are the care providers of the children, so they can make wiser choices when feeding their children. Programs already exist in schools to educate children about healthy diets and to improve the consumption of vegetables and fruits. Since Michelle Obama started focusing on eliminating obesity in the United States. Schools now provide more choices of fruits and vegetables for the children. However, we would still get involved with schools in the community to work on making a school garden for the children to learn how vegetables and fruits are grown. We would also work on providing monthly education about diet during school hours, to maintain the change and impregnate the importance of healthy diet in the child's mind since an early age. The implementation of education about making better choices when choosing food will lead to less obesity and a healthier population and eventually decreasing the healthcare cost and prolonging the health and life of the population.

As community health nurse we would also provide the Hispanic population with plenty education about the harming of unhealthy diet and the benefits that a healthy diet can bring. I would also work on empowering the community and assist to make changes in the entire community by working on building a community and school garden to have help the community to enjoy fresh vegetables while teaching children the rewarding feeling of planting and enjoying the fruits of their labor by providing the their 
families or to the community by having a farmers market. We would also work with small liquor stores and markets to replace products such sodas and chips with fruits and vegetables where is visual for the customers and replace posters of cigarettes and sodas with posters of fruits and vegetables. The small business changes we believe it would be one of the most changes since their income depends on sales. We would educate the business owner and sick support from local government to come up with a plan to support small businesses owner to join the program such as only buying vegetables and fruits from the small business owners during community events or lowering the price of fruits and vegetable for small business owner which would lead to increase their income.

As a community health nurse we would follow up on the implementation and education to the community. For people to change consistence, follow up and some type of rewarding is essential. We would ensure to follow with the families that we initiated the change in their diet by phone call or home visits and we would gain permission to check their refrigerators and assess their weight loss in exchange for the family success in changing their diet or losing weight we would provide movie theater tickets or a gift card for the farmers market. These gift cards would be purchased with the collaboration and donation of community business owners.

\section{CONCLUSIONS}

Since diet is not the only way to change the high obesity rate for the Hispanic community we would also work to improve exercising activities in the community by asking the collaboration of YMCA club to provide low rate membership to get more Hispanic families to become a member. We would work with Boys and Girls Club to emphasize on the importance of providing the children's activities and reduce computer usage. We would also work with the community center to provide monthly activities such as marathons for children and adults or exercise classes for mommy and me to reinforce mother and child bonding. There are many things that can be done to bring awareness and healthy habits change into the Hispanic community.

However, for the changes to happen it must be a collaborative effort and the health community nurse is at the center and is the one responsible to keep the connection between all the parties to successfully implement healthy habits changes and to maintain the changes.

\section{REFERENCE}

Centers for Disease Control and Prevention, (2014). Chronic diseases and health promotion. Retrieved on March 22, 20015.

ChooseMyPlate.gov Website. Washington, DC. About us. Retrieved from http://www.choosemyplate.gov/about.html

Schiller J, Lucas J, Ward B, Peregoy J. Summary health statistics for U.S.adults: National Health Interview Survey, 2010. National Center for Health Statistics. Vital Health Stat 10 2012;(252):1-207.

Valen, M. , Narayan, S. , \& Wedeking, L. (2012). An innovative approach to diabetes education for a hispanic population utilizing community health workers. Journal of Cultural Diversity, 19(1), 10. 
[1] Registered Nurse e Bachelors in Nursing Science. USA - California

[2] PhD in Clinical Psychoanalysis, Researcher at the Center for Research and Advanced Studies.

[3] Biologist. Doctor of Medicine / Tropical Diseases. Professor and Researcher at the Federal University of Pará - UFPA. Researcher at the Laboratory of Human and Environmental Toxicology and in the Laboratory of Oxidative Stress of the Nucleus of Tropical Medicine of UFPA (NMT-UFPA).

\section{PUBLIQUE SEU ARTIGO CIENTÍFICO EM:}

https://www.nucleodoconhecimento.com.br/enviar-artigo-cientifico-para-submissao 